\title{
Influence of driver nationality on the risk of causing vehicle collisions in Spain
}

\author{
P Lardelli Claret, J D Luna del Castillo, J J Jiménez Moleón, A Bueno Cavanillas, \\ M García Martín, R Gálvez Vargas
}

See end of article for authors' affiliations

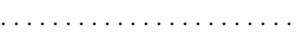

Correspondence to: Dr P Lardelli-Claret,

Departamento de Medicina Preventiva y Salud Pública, Facultad de Farmacia,

Campus de Cartuja s/n, 18071 Granada, Spain; lardelli@ugr.es

Accepted for publication 8 October 2001

\begin{abstract}
Study objective: To estimate the association between driver nationality and the risk of causing a collision between vehicles in motion.

Design: Retrospective, matched by collision, case-control study.

Setting: Collisions that occurred in Spain during the period from 1990 to 1999 were studied.

Participants: Responsible (case) and non-responsible (control) drivers identified in the databases of the Dirección General de Tráfico (General Traffic Directorate) who were involved in a collisions between two or more four wheeled vehicles in motion, in which only one of the drivers had committed a traffic violation.

Main results: Crude odds ratios (ORs) for the effect of driver nationality on the risk of causing a collision were significantly higher for foreign drivers than for Spanish drivers, and ranged from a minimum of $1.19(95 \% \mathrm{Cl} 1.09$ to 1.29$)$ for Portuguese drivers to a maximum of 2.06 (1.88 to 2.27) for British drivers. Corresponding adjusted ORs were slightly lower, but were still significantly higher than 1 for all nationalities except Italian, Belgian, and American (USA). Adjusted ORs were usually higher for collisions that occurred in urban areas than on open roads.

Conclusions: Authorities responsible for traffic safety, and drivers in general, should consider foreign drivers in Spain at particularly high risk for causing collisions, especially in urban areas.
\end{abstract}

$\mathrm{T}$ raffic accidents continue to be a problem of considerable magnitude in Spain. According to data from the Dirección General de Tráfico (General Directorate of Traffic, hereafter DGT), in 1999 there were 97811 accidents with victims, which resulted in 5738 deaths and 142894 persons injured. ${ }^{1}$ In a 1996 report, the National Epidemiology Centre noted that motor vehicle accidents were the ninth most frequent cause of death in men and the 20th most frequent in women, with age adjusted mortality rates of 19.9 and 5.6 per 100000 inhabitants respectively. ${ }^{2}$ The effect of traffic accidents is even more striking in terms of potential years of life lost, as most accidents involve young people. Vehicle crashes are the second most frequent cause of potential years of life lost among men and the third most frequent cause among women. ${ }^{2} \mathrm{~A}$ worrying trend is that the decline in the accident and mortality rates seen in the early 1990s seems to have halted in recent years. ${ }^{2}$ Unfortunately, Spain occupies a place near the head of the list when traffic crashes deaths per total population are compared across European countries. ${ }^{3}$

Risk factors for involvement in a traffic accident are often classified into three large groups: driver dependent (or pedestrian dependent for accidents between a vehicle and a pedestrian), vehicle related, and environment dependent. ${ }^{45}$ Most authors attribute most accidents to driver dependent factors, which are thought to account for $60 \%$ to $90 \%$ of all traffic accidents. ${ }^{6-8}$ In many countries including Spain, this belief has led to emphasis on training in traffic regulations (for both drivers and pedestrians) in programmes aimed at preventing traffic accidents. ${ }^{79}$

In view of the situation described above, much of the difference in accident and mortality rates between countries might be attributable to differences in driving skills. However, this hypothesis is hard, if not impossible, to test: a representative sample of drivers from each country would need to be exposed to a neutral driving environment for a sufficiently long period-a set of conditions that obviously cannot be created experimentally.
Spain, a popular tourist destination, receives large numbers of foreign drivers each year, especially during the summer holiday season. These drivers, which constitute a nonrepresentative sample of all drivers in their country of origin, drive in an unknown (and hence hostile) environment. None the less, if the driving skills of Spanish drivers were much worse than those of drivers from other countries, the risk of causing a collision in Spain would be higher for Spanish drivers than for foreign drivers.

Regardless of the evidence for or against this hypothesis, estimates of foreign drivers' risk of causing a collision are clearly of interest to both traffic safety authorities and other drivers, in view of the large numbers of such drivers in Spain. The aim of this study was therefore to estimate the association between driver nationality and risk of causing a collision between vehicles in movement in Spain during the period from 1990 to 1999.

\section{METHODS}

The study design is based on a specific application of the induced exposure technique ${ }^{10} 11$ according to a method similar to that used in a 1991 study by Perneger and Smith. ${ }^{12}$ It is a retrospective, paired case-control study with a variable number of controls per case. The data we analysed were from the DGT registers of traffic accidents with victims. These registers contain information from the traffic accident reports that the Spanish police are required to file for every crash with victims. For the period of study this register contains data from 895949 traffic accidents with victims, 46473 (5.19\%) of which resulted in at least one death. The accidents involved 1527351 drivers, 79162 (5.18\%) of whom were non-Spanish or for whom no nationality was recorded. One of the variables we recorded was which of 20 possible traffic violations (if any) was committed (see appendix 1) by each of the drivers involved in the accident. The type of infraction was used to classify drivers as infractors or non-infractors. We selected 
Table 1 Distribution of drivers by country and responsibility for collision, and crude and adjusted odds ratios for the effect of each nationality

\begin{tabular}{|c|c|c|c|c|c|c|c|c|c|c|}
\hline \multirow[b]{3}{*}{ Country } & \multicolumn{6}{|c|}{ Number of drivers (raw data) } & \multicolumn{4}{|c|}{ Odds ratios and $95 \%$ confidence intervals } \\
\hline & \multicolumn{2}{|l|}{ Total } & \multicolumn{2}{|c|}{ Responsible } & \multicolumn{2}{|c|}{ Non-responsible } & \multicolumn{2}{|c|}{$\begin{array}{l}\text { Crude analysis } \\
\text { (number of drivers = } \\
490009 \text { ) }\end{array}$} & \multicolumn{2}{|c|}{$\begin{array}{l}\text { Adjusted analysis* } \\
\text { (number of drivers }= \\
313902 \text { ) }\end{array}$} \\
\hline & $\mathrm{N}$ & $\%$ & $\mathrm{~N}$ & $\%$ & $\mathrm{~N}$ & $\%$ & cOR & $95 \% \mathrm{Cl}$ & $\mathrm{aOR}$ & $95 \% \mathrm{Cl}$ \\
\hline Spain & 470136 & 95.94 & 215204 & 95.15 & 254932 & 96.62 & $1.00 \dagger$ & - & $1.00 \dagger$ & - \\
\hline France & 3525 & 0.72 & 1798 & 0.79 & 1727 & 0.65 & 1.33 & 1.24 to 1.43 & 1.28 & 1.15 to 1.42 \\
\hline Germany & 2696 & 0.55 & 1412 & 0.62 & 1284 & 0.49 & 1.38 & 1.27 to 1.49 & 1.36 & 1.20 to 1.53 \\
\hline Morocco & 2557 & 0.52 & 1578 & 0.70 & 979 & 0.37 & 2.02 & 1.86 to 2.20 & 1.65 & 1.45 to 1.88 \\
\hline Portugal & 2509 & 0.51 & 1224 & 0.54 & 1285 & 0.49 & 1.19 & 1.09 to 1.29 & 1.15 & 1.01 to 1.30 \\
\hline Great Britain & 2009 & 0.41 & 1244 & 0.55 & 765 & 0.29 & 2.06 & 1.88 to 2.27 & 2.16 & 1.87 to 2.51 \\
\hline Italy & 863 & 0.18 & 449 & 0.20 & 414 & 0.16 & 1.35 & 1.17 to 1.54 & 1.18 & 0.94 to 1.47 \\
\hline Netherlands & 613 & 0.13 & 341 & 0.15 & 272 & 0.10 & 1.59 & 1.34 to 1.87 & 1.46 & 1.13 to 1.87 \\
\hline Belgium & 527 & 0.11 & 256 & 0.11 & 271 & 0.10 & 1.18 & 0.99 to 1.41 & 1.09 & 0.83 to 1.43 \\
\hline Switzerland & 507 & 0.10 & 294 & 0.13 & 213 & 0.08 & 1.73 & 1.45 to 2.08 & 1.68 & 1.29 to 2.20 \\
\hline USA & 282 & 0.06 & 170 & 0.08 & 112 & 0.04 & 1.88 & 1.47 to 2.40 & 1.47 & 0.98 to 2.21 \\
\hline Other countries & 3785 & 0.77 & 2198 & 0.97 & 1587 & 0.60 & 1.73 & 1.61 to 1.85 & 1.45 & 1.30 to 1.62 \\
\hline
\end{tabular}

only those collisions that involved two or more vehicles in motion with four or more wheels, and in which only one of the drivers involved was considered an infractor. Therefore, of the total of 519227 collisions involving at least two vehicles registered in the DGT database, we excluded those that involved a stopped or parked vehicle or two wheeled vehicle, those in which none or more than one of the drivers was considered an infractor, and those in which the nationality of one or more of the drivers was not stated.

The rationale of the study was as follows: in those collisions in which only one driver committed an infraction, this driver can be considered responsible for the collision. The involvement of the other drivers (non-infractors) can be assumed to be passive, and these drivers can be considered a representative sample of all drivers on the road at the time of the collision. Hence the responsible drivers (infractors) constituted the case group. For each case the non-responsible driver(s) involved in the same collision were used as paired controls. (Many cases had only 1 control, others had 2 or more.) The final sample comprised 226168 responsible drivers involved in as many collisions (representing $25.24 \%$ of all accidents registered in the DGT database, and $43.56 \%$ of all collisions), and 263841 non-responsible drivers. Of all collisions studied, $11694(5.17 \%)$ resulted in at least one death.

For each driver we recorded the following variables, which were coded in the DGT database: nationality (Spanish, Portuguese, French, Moroccan, German, British, Italian, Swiss, Belgian, Dutch, American (USA), other), sex, age, psychophysical circumstances (normal, under the influence of alcohol as documented by a positive breath test, under the influence of other drugs, sudden illness, sleepiness or drowsiness, other), administrative infraction (none, driving licence expired, motor vehicle inspection certificate expired, other), speed related infractions (none, inappropriate speed for the road or whether conditions, speeding, slow driving that interfered with traffic), physical disabilities (none, sight, hearing, upper limbs, lower limbs, other), years in possession of driving licence, years since the vehicle was registered for driving on public roads, type of driver (professional or non-professional), and safety belt use at the time of the accident (included as a surrogate measure of safety awareness). The month in which the accident occurred, and whether the accident occurred within city limits or on the open road was also recorded. Age was stratified into five year intervals with the exception of the 18 year old to 24 year old group ( 18 years is the minimum legal driving age in Spain) and the $>74$ year old group (the sample contained very few women drivers aged $>74$ years).

To estimate odds ratios with a 95\% confidence intervals (CI) for each nationality (with Spanish nationality as the reference), we analysed the findings with conditional logistic regression, ${ }^{13}$ using responsible versus non-responsible driver as the dependent variable. Crude (COR) and adjusted odds ratios (aOR) were calculated, the latter by including in the model all of the remaining driver related and vehicle related variables at once. None of the variables could be removed from the model according to the pre-established $\mathrm{p}$ to remove value $(p>0.05)$. The results were stratified according to the period in which the accident occurred (from June to September inclusive or during the rest of the year), and whether the collision occurred within city limits or on an open road. All analyses were done with the STATA statistical package (version 5.0). ${ }^{.4}$

\section{RESULTS}

Of all drivers involved in the sample of collisions we studied, $4.06 \%$ were foreign drivers. For this group, the cOR for causing a collision, in comparison with Spanish drivers, was 1.55 (95\% CI: 1.50 to 1.60$)$. After adjustment for all other driver characteristics, the aOR was slightly lower: 1.42 (95\% CI: 1.35 to 1.49). Table 1 shows the distribution of drivers involved in collisions according to responsibility and nationality. The most frequent non-Spanish nationality was French $(0.72 \%)$, followed by German $(0.55 \%)$, Moroccan $(0.52 \%)$ and Portuguese $(0.51 \%)$. Table 1 also summarises the estimated cOR and aOR for each nationality. In the crude analysis all ORs except the estimate for Belgian drivers were significantly greater than 1, with values ranging from 2.06 (British) to 1.19 (Portuguese). Adjusted ORs were slightly lower than crude estimates except for British drivers; in this subgroup the aOR was 2.16. Despite the slightly lower associations in comparison with cORs, the aORs still showed significant associations between nationality and risk of causing a vehicle collision for all nationalities except Italian, Belgian, and American (USA).

Table 2 shows the aORs stratified for type of road where the collision took place (urban area or open road). The aORs for collisions that occurred in cities or towns were higher than the estimates for crashes on open roads for all nationalities except Swiss and Dutch, although the reduction of sample size resulted in a loss of statistical significance for several aOR in urban areas. The highest aORs on open roads were found for 
Table 2 Adjusted odds ratio for the effect of nationality on responsibility, stratified by zone of occurrence of the collision*

\begin{tabular}{|c|c|c|c|c|}
\hline \multirow[b]{2}{*}{ Country } & \multicolumn{2}{|c|}{$\begin{array}{l}\text { Open road (number of drivers = } \\
\text { 208979) }\end{array}$} & \multicolumn{2}{|c|}{ Urban (number of drivers $=84202$ ) } \\
\hline & $\mathrm{aOR}+$ & $95 \% \mathrm{Cl}$ & aOR† & $95 \% \mathrm{Cl}$ \\
\hline Spain & $1.00 \ddagger$ & - & $1.00 \ddagger$ & - \\
\hline France & 1.21 & 1.08 to 1.35 & 2.24 & 1.56 to 3.23 \\
\hline Germany & 1.32 & 1.16 to 1.51 & 1.66 & 1.12 to 2.47 \\
\hline Morocco & 1.54 & 1.34 to 1.79 & 2.38 & 1.59 to 3.54 \\
\hline Portugal & 1.16 & 1.01 to 1.32 & 1.38 & 0.88 to 2.17 \\
\hline Great Britain & 2.15 & 1.84 to 2.52 & 2.35 & 1.30 to 4.24 \\
\hline Italy & 1.22 & 0.96 to 1.57 & 1.45 & 0.75 to 2.81 \\
\hline Netherlands & 1.48 & 1.13 to 1.94 & 1.22 & 0.55 to 2.75 \\
\hline Belgium & 1.11 & 0.83 to 1.47 & 1.58 & 0.51 to 4.92 \\
\hline Switzerland & 1.78 & 1.33 to 2.37 & 1.10 & 0.42 to 2.90 \\
\hline U.S.A. & 1.25 & 0.80 to 1.96 & 4.78 & 1.18 to 19.46 \\
\hline Other countries & 1.44 & 1.27 to 1.64 & 1.59 & 1.23 to 2.06 \\
\hline
\end{tabular}

*Accidents that occurred on throughways (20721 drivers) were excluded from the analysis; †aOR: adjusted odds ratios. Variables entered in the model: age, sex, administrative infraction, speeding infraction, psychophysical circumstances, years in possession of driving licence, professional or non-professional driver, physical disabilities, safety belt use, years since the vehicle involved was registered for driving on public roads; łreference category.

Table 3 Adjusted odds ratio for the effect of nationality on responsibility, stratified by period of occurrence of the collision

\begin{tabular}{|c|c|c|c|c|}
\hline \multirow[b]{2}{*}{ Country } & \multicolumn{2}{|c|}{$\begin{array}{l}\text { Non-holidays (October-May) (number } \\
\text { of drivers = 204251) }\end{array}$} & \multicolumn{2}{|c|}{$\begin{array}{l}\text { Holidays (June-September) (number } \\
\text { of drivers = 109651) }\end{array}$} \\
\hline & $a O R^{*}$ & $95 \% \mathrm{Cl}$ & $a O R^{*}$ & $95 \% \mathrm{Cl}$ \\
\hline Spain & $1.00 \dagger$ & - & $1.00 \dagger$ & - \\
\hline France & 1.31 & 1.12 to 1.54 & 1.25 & 1.09 to 1.44 \\
\hline Germany & 1.45 & 1.23 to 1.71 & 1.24 & 1.04 to 1.49 \\
\hline Morocco & 1.75 & 1.47 to 2.09 & 1.54 & 1.26 to 1.88 \\
\hline Portugal & 1.17 & 0.99 to 1.38 & 1.11 & 0.92 to 1.34 \\
\hline Great Britain & 2.03 & 1.67 to 2.47 & 2.34 & 1.87 to 2.94 \\
\hline Italy & 1.30 & 0.93 to 1.83 & 1.09 & 0.81 to 1.47 \\
\hline Netherlands & 1.24 & 0.87 to 1.76 & 1.73 & 1.20 to 2.48 \\
\hline Belgium & 1.03 & 0.69 to 1.53 & 1.14 & 0.78 to 1.67 \\
\hline Switzerland & 1.63 & 1.13 to 2.36 & 1.73 & 1.17 to 2.57 \\
\hline USA & 1.54 & 0.86 to 2.74 & 1.40 & 0.78 to 2.49 \\
\hline Other countries & 1.31 & 1.13 to 1.52 & 1.65 & 1.39 to 1.96 \\
\hline
\end{tabular}

British drivers (2.15). For accidents within city limits, high aORs were also found for British drivers (2.35), and for drivers from France (2.24), Morocco (2.38), and especially from the USA (4.78).

Table 3 shows the aORs stratified for the period when the collision occurred (summer versus rest of the year). The magnitude and statistical significance of the aORs for each country were similar for both periods, and no general pattern of excess risk in association with the summer season was evident. Only Dutch drivers had an aOR that was appreciably higher during the holiday season (1.73) than during the rest of the year (1.24)

\section{DISCUSSION}

Our results show that vehicle collisions in Spain during the period from 1990 to 1999 were more likely to have been caused by non-Spanish than by Spanish drivers. The difference was especially clear for crashes that took place within city limits. The possible explanations for our findings are discussed below.

\section{Influence of driver related characteristics}

Drivers from other countries who are at the wheel of motor vehicles on Spanish roads may not be representative of the total population of drivers in their respective countries. If this were shown to be true, it would be difficult to evaluate the influence of possible selection biases, as the baseline risk of causing a collision while driving in their country of origin is unknown. In particular, it seems evident that in Spain, many foreign drivers are tourists whose behaviour behind the wheel, perhaps in association with a greater risk of causing a collision, might be notably different from that of the rest of the drivers from the same country. However, when the data were stratified for season of the year (summer holiday versus rest of the year), no significant difference was found between the two periods.

Drivers may change their driving habits when they are abroad. This factor seems to have been influential for British drivers, who are used to driving in the left rather than the right lane, and for Moroccan drivers residing in central and northern Europe, most of whom drive across Spain from north to south or vice versa with very little time for rest stops on their way to Morocco for their summer holiday or on their way back to their place of habitual residence. It is not surprising that the cORs for British and Moroccan drivers were higher than for all other nationalities, and that the adjusted OR for Moroccan drivers was much lower than the crude OR when the analysis was adjusted for psychophysical circumstances. 


\section{Key points}

- Traffic crashes are a major health problem in all developed countries.

- Traffic crash indicators vary widely between developed countries.

- Foreign drivers driving in Spain are at greater risk of causing collisions than are Spanish drivers. The highest risk was found for British and Moroccan drivers.

- The excess of risk for foreign drivers is higher in urban areas than on open roads.

- Foreign drivers driving in Spain should be considered a high risk group by Spanish drivers and traffic safety authorities.

If most foreign drivers in Spain are assumed not to reside habitually in this country, unfamiliarity with the Spanish driving milieu can undoubtedly be an important factor in their higher propensity to cause collisions. This assumption is supported by the generally higher aORs for city driving, where unfamiliarity with local driving conditions is greater.

\section{Influence of classification bias}

Another possible explanation for the higher risk of causing a vehicle collision among non-Spanish drivers is bias in the ascription of responsibility for the crash: the police agents responsible for preparing the accident report may be more likely to blame foreign rather than Spanish drivers. However, when we stratified the analysis according to type of infraction, the magnitudes of the OR remained mostly unchanged in relation with such straightforward infractions as driving in the opposite lane or disobeying a traffic light (data not shown)

\section{Methodological considerations}

Some methodological considerations need to be discussed. Firstly, we assumed that the drivers identified in the DGT register as infractors were responsible for the accident they were involved in. Although committing traffic violations while driving is closely related with the risk of involvement in an accident, ${ }^{15}{ }^{16}$ committing a traffic violation does not usually lead to an accident under actual driving conditions. However, for a given collision involving one infractor and one or more other drivers who committed no infraction, the chances that the infractor was responsible for the accident can safely be assumed to be much greater than the chances that a non-infractor was responsible. We therefore assumed that most of the infractors in our sample were responsible for the accident, and that most of the non-infractors were not responsible. Evidently, the bias arising from the small proportion of misclassified drivers (that is, non-responsible infractors and responsible non-infractors) would tend toward the null, hence the overall effect would be to underestimate the association between being an infractor and the risk of causing an accident. Indirect support for the validity of our design comes from the finding that the associations we found between risk of causing an accident and each of the other covariables were consistent with the results of earlier studies (data not shown).

This study, based as it is on the induced exposure method, is subject to the advantages and disadvantages of this approach ${ }^{17}$ The main advantage of the design developed by Perneger and Smith ${ }^{12}$ is that by pairing drivers according the collision they were involved in, the confounding effect of the main environmental factors is controlled for. With respect to its limitations, the induced exposure method reportedly underestimates exposure in more careful drivers-that is, those who use a particularly conservative driving strategy and are therefore passively involved in collisions less frequently than their actual exposure would warrant. ${ }^{18}$ This may be the

\section{Policy implications}

\section{Short-term: Road education and information} National Traffic Agency:

- Road education for the general population: The importance of ignorance of local road conditions as a risk factor for traffic crashes.

- For national drivers: Information about foreign drivers' higher risk of causing collisions, in relation with their lack of knowledge of the Spanish driving environment.

- For non-resident foreign drivers: Near the Spanish border, at tollgates and in service areas, brochures with detailed information about foreign drivers' higher risk of causing collisions in Spain, the particularities of Spanish roads and road signs, and the main black spots of each route.

\section{Local Authorities}

- Local authorities could provide city maps in hotels and tourist offices, indicating the best routes to the main places of interest, and alternative public transportation services available.

Medium term: Improvements in road signs, urban public transport, and road infrastructure

National Traffic Agency and Local Authorities

- Increase resources to improve road signs in open roads and urban areas. Use other languages in addition to Spanish for road signs (specifically, Arabic in certain areas and on certain routes).

- Local Authorities: Improve public transportation in urban areas, and publicize these services more effectively to tourists.

National and Regional Public Works Authorities

- Improve road infrastructure: Rest and service areas and ring roads.

Long term: Information systems and road safety

policies

- Develop a unified European database of traffic crashes

- Reorient national policies for road safety, increasing the resources and interventions aimed at improving road and other environmental conditions.

case for foreign (non-Spanish) drivers who use an especially conservative driving style when they are abroad (or at least when they are in Spain).

A final note of caution is in order regarding the adjusted analysis. Our analysis was done in a manner that controlled for the effect of the main driver related and vehicle related covariables (age, psychophysical circumstances, speeding, etc). This approach was used to reduce, as far as possible, confusion in the association between nationality and risk of causing a collision. However, because some data for some of the covariables included in the model were missing, the adjusted analysis comprised only $64 \%$ of the initial sample of drivers. In an attempt to elucidate whether this lack of data might have introduced selection bias in our adjusted estimates, we obtained crude estimates of the effect of nationality in the subsample of drivers not included in the adjusted analysis. The estimates were quite similar to those obtained for the whole sample, with a tendency toward greater cORs. For foreign drivers considered globally, the cOR for the subsample of excluded drivers was 1.69 , a figure $9 \%$ higher than that obtained for the whole sample (1.55). When the cOR was estimated for each nationality, 8 of the 11 estimates also yielded values slightly higher than the corresponding values obtained for all drivers. This result suggests that the aORs obtained in our study might have been affected by a slight bias towards the null.

In conclusion, the results of this study should not be taken to imply that the intrinsically poor driving habits of foreign 
drivers in Spain place them at greater risk for causing a vehicle collision than Spanish drivers. The difference in risk is in fact probably attributable to the combined effect of some or all of the factors discussed above. None the less, both the authorities responsible for traffic safety and all other drivers on Spanish roads should consider foreign drivers a special risk group, especially within city limits. On the basis of a simple calculation of the per cent population attributable risk (estimated from a global aOR of 1.42 for foreign drivers, and a proportion of exposed (foreign) cases (responsible drivers) of $4.8 \%$ ), approximately $1.4 \%$ of the collisions we analysed can be attributed to foreign drivers in Spain. On the other hand, it seems obvious that given the same driving environment, the risk of Spanish drivers causing a collision is no greater than that of drivers of other nationalities.

\section{ACKNOWLEDGEMENTS}

We thank the Dirección General de Tráfico of Spain for providing the raw data from their traffic accident database, and $\mathrm{K}$ Shashok for translating the manuscript into English.

Funding: this study was supported by the Fondo de Investigaciones Sanitarias of the Spanish Ministry of Health and Consumer Affairs through project no 00/0722.

Conflicts of interest: none.

\section{Authors' affiliations}

P Lardelli Claret, J J Jiménez Moleón, A Bueno Cavanillas,

M García Martín, R Gálvez Vargas, Department of Preventive

Medicine and Public Health, University of Granada, Granada, Spain

J D Luna del Castillo, Department of Statistics, University of Granada

\begin{tabular}{llll} 
Appendix 1 & Traffic infractions recorded bny the Spanish Dirección General de Tráfico & \\
\hline Code & Infraction & Number & $\%$ \\
\hline 01 & Distracted or inattentive* & 34433 & 7.03 \\
11 & Incorrect use of vehicle lights/failure to use low beams for oncoming vehicles ${ }^{*}$ & 169 & 0.03 \\
21 & Driving in the wrong lane or in the wrong direction & 10169 & 2.08 \\
22 & Partially invading opposite lane* & 20078 & 4.10 \\
23 & Incorrect turn & 13560 & 2.77 \\
24 & Illegal passing & 12120 & 2.47 \\
25 & Zig-zagging & 524 & 0.11 \\
31 & Violating the minimum safety distance between vehicles & 25513 & 5.21 \\
32 & Unjustified braking & 287 & 0.06 \\
41 & Failure to grant right of way & 15296 & 3.12 \\
42 & Disobeying a traffic light & 15768 & 3.22 \\
43 & Disobeying a stop sign & 26918 & 5.49 \\
44 & Disobeying a yield sign & 15341 & 3.13 \\
45 & Invading a pedestrian crossing & 50 & 0.01 \\
46 & Disobeying any other traffic sign or a police instruction & 937 & 0.19 \\
51 & Failure to correctly signal intention & 462 & 0.09 \\
52 & Entering traffic flow carelessly & 3109 & 0.63 \\
53 & Stopping in an illegal or dangerous place & 220 & 0.04 \\
71 & Opening vehicle door into traffic & 173 & 0.04 \\
81 & Other infraction & 31041 & 6.33 \\
91 & No infraction & 263841 & 53.84 \\
\hline
\end{tabular}

*Not coded in the database during 1990-1992; +not coded in the database during 1993-1999.

\section{REFERENCES}

1 Dirección General de Tráfico. Anuario accidentes 1999. Madrid, Ministerio del Interior, Dirección General de Tráfico, 1999 (http://www.dgt.es/)

2 Centro Nacional de Epidemiología. Mortalidad en España en 1996. Mortalidad general, principales causas de muerte y de años potenciales de vida perdidos. Mortalidad en jóvenes. Boletín Epidemiológico Semanal 1999; sSemana 38, no 16:169-76.

3 Organisation for Economic Co-operation and Development International Road Traffic and Accident Data. Paris: OECD, May 2000 (http://www.oecd.org/dsti/sti/transpor/road/stats/index.htm)

4 Haddon WH Jr. Advances in the epidemiology of injuries as a basis for public policy. Public Health Rep 1980;95:411-21.

5 Robertson LS. Injury epidemiology. 2nd edn. New York: Oxford University Press, 1998.

6 Evans L. Comment: the dominant role of driver behaviour in traffic safety. Am J Public Health 1996;86:784-6.

7 Comisión Especial de Encuesta e Investigación sobre los problemas derivados del uso del automóvil y de la seguridad vial. Dictamen de la Comisión Especial de Encuesta e Investigación sobre los problemas derivados del uso del automóvil y de la seguridad vial. Madrid: Senado, 1992

8 Gerència de Seguretat Vial. El llibre blanc de la seguretat vial. Barcelona: Departament de la Governació, Generalitat de Catalunya, 1992:51.
9 Pedragossa JL. La organización y los modelos de prevención como factores básicos de una estrategia de seguridad vial. Carreteras 1994:72:61-8.

10 Stamatiadis M, Deacon J. Quasi-induced exposure: methodology and insight. Accid Anal Prev 1997;29:37-52.

11 DeYoung DJ, Peck RC, Helander CJ. Estimating the exposure and fatal crash rates of suspended/revoked and unlicensed drivers in California. Accid Anal Prev 1997; 29:17-23.

12 Perneger T, Smith GS. The driver's role in fatal two-car crashes: a paired "case-control study". Am J Epidemiol 1991;134:1138-45.

13 Hosmer DW, Lemeshow S. Applied logistic regression. New York: Wiley, 1989.

14 StataCorp. Stata statistical software: Release 5.0. College Station, TX: Stata Corporation, 1997

15 Lourens PF, Vissers JAMM, Jessurun M. Annual mileage, driving violations, and accident involvement in relation to driver's sex, age and level of education. Accid Anal Prev 1999;31:593-7.

16 Simon F, Corbett C. Road traffic offending, stress, age, and accident history among male and female drivers. Ergonomics 1996;39: 757-80.

17 Lyles RW, Stamatiadis P, Lighthizer DR. Quasi-induced exposure revisited. Accid Anal Prev 1991;23:275-85.

18 Hakamies-Blomqvist L, Peters B. Recent European research on older drivers. Accid Anal Prev 2000;32:601-7. 